\title{
Sensitivity to endotoxin is induced by increased membrane fatty-acid unsaturation and oxidant stress
}

\author{
J. M. STARK and S. K. JACKSON
}

\section{Department of Medical Microbiology, University of Wales College of Medicine, Cardiff CF4 4XN}

\begin{abstract}
Summary. The mechanisms modulating host susceptibility to endotoxin are unknown. Evidence suggests that endotoxin pathophysiology is mediated in part by oxidative reactions that lead to tissue damage and organ failure. The proposition is that conditions which favour oxidation sensitise the host to endotoxin. Central to this hypothesis is that an increase in the polyunsaturated fatty-acid composition of membrane phospholipids enhances susceptibility because such fatty acids are easily oxidised to produce mediators of the endotoxic crisis. Cytokines, such as tumournecrosis factor and interferon- $\gamma$, may be ultimately responsible for orchestrating these changes and thereby modify the host response to endotoxin.
\end{abstract}

\section{Variations in endotoxin sensitivity}

It is a matter of common clinical observation in intensive-care units that patients who experience shock induced by bacterial endotoxin fall into two main groups: those who are highly sensitive and die rapidly; and those who appear to be less sensitive and who survive for at least several days. What exactly determines the outcome is a matter of conjecture. It may rest on some specific factor, such as amount of absorbed endotoxin or circulating antibody, or may be based on as yet undefined, nonspecific factors. Nevertheless, it is important to try to define the basis in order to develop rational therapy. Therefore, it is worth considering what may be gleaned from observations in animals on endotoxin sensitivity so that the critical mechanisms might be deduced and appropriate observations made in patients. Endotoxin upsets many mechanisms and cascade systems and the critical ones may be hard to pinpoint. Those preliminaries (table) which modulate endotoxin sensitivity in animals may afford clues to the dominant mechanisms and suggest further observations in man.

Received 10 Dec. 1989; accepted 29 Jan. 1990.

\section{Influence of previously established infective processes}

In 1961 Suter and Kirsanow ${ }^{1}$ exploited observations made in several species to develop a model whereby mice could be made 1000 to 500000 times more sensitive to endotoxin by the previous settingup of a widespread infection with attenuated mycobacteria of Bacille Calmette Guérin (BCG). They cited bacterial, viral and protozoal infections in a number of species, including man, in which the host thereby had been sensitised to endotoxin. These included infections with Vibrio cholerae in rabbits; Mycobacterium tuberculosis in mice and guinea-pigs; Eperythrozoon coccoides in mice; Salmonella typhi in man; hepatitis virus in mice; and variola vaccine in rabbits. The deduction is that there is something common to the inflammation in each infection that sensitises the animal to endotoxin.

In the Suter-Kirsanow model, the liver and spleen contain greatly increased numbers of stimulated macrophages within miliary granulomata. The potential products of these cells must be regarded as important. In addition to producing oxygen free radicals, they are, of course, likely to be the source of cytokines, the output of which would be greatly accentuated after endotoxin.

Thus, sensitisation to endotoxin has been noted in several species in which the host has an infection, 
Table. Shwartzman-type reactions

\begin{tabular}{|c|c|c|c|}
\hline Species & $\begin{array}{l}\text { Sensitisation } \\
\text { with }\end{array}$ & $\begin{array}{l}\text { Provocation } \\
\text { with }\end{array}$ & Reference \\
\hline Rabbit & Endotoxin & Endotoxin & 2,3 \\
\hline Mouse & BCG & Endotoxin & 1 \\
\hline Rabbit & Pregnancy & Endotoxin & 9 \\
\hline Rat & Pregnancy & Endotoxin & 10 \\
\hline Rat & Pregnancy and vitamin-E deficiency & $\ldots$ & 11 \\
\hline & Pregnancy and peroxidised oil & & 13 \\
\hline Rabbit & TNF and interleukin I & Endotoxin & 4 \\
\hline Mouse & Endotoxin & TNF & 5 \\
\hline
\end{tabular}

often of a non-endotoxic type. The fact that such infections may non-specifically influence sensitisation suggests that this is an appropriate item for study, as it appears to be a natural and general process.

\section{Sanarelli-Shwartzman reactions}

Sensitisation to endotoxin may not only be brought about by infection with live organisms but also may be set up by previous experience of endotoxin itself within a limited interval beforehand. In these classical reactions in the rabbit (described by Sanarelli ${ }^{2}$ and Shwartzman ${ }^{3}$ ), after an initial local or systemic "sensitising" dose, local or generalised reactions, respectively, take place when, $24 \mathrm{~h}$ later, the intravenous "provoking" endotoxin dose is given.

\section{Role of cytokines in Shwartzman-type reactions and endotoxic states}

The most remarkable "sensitising" and "provoking" reactions of the Shwartzman type are those in which cytokines have been used. In rabbits interleukin I and tumour-necrosis factor (TNF) together may sensitise to endotoxin ${ }^{4}$ or, alternatively, endotoxin may sensitise to the subsequent use of TNF.

In mice, endotoxin may be given first, locally, as sensitiser and the skin will react to the administration of TNF 24 h later. ${ }^{5}$ Interferon- $\gamma$ may contribute to these reactions, because antibody against it will prevent local and general effects of endotoxin in mice. ${ }^{6}$ In the infective crisis of meningococcal endotoxaemia with purpuric manifestations, high concentrations of TNF and interferon- $\gamma$ have been found in the bloodstream. ${ }^{7}$

It would appear, therefore, that endotoxin sensi- tivity is related to the ability to produce and release increased amounts of cytokines during an infection and that this ability is common to the various sensitising infected states mentioned above.

BCG infection is known to lead to the production of TNF and interferon- $\gamma .{ }^{8}$ The evidence suggests that cytokines produced in these states will induce hypersensitivity to endotoxin in the host and, thus, that they are central to the development of endotoxin sensitivity.

\section{Increased pro-oxidant load — the endogenous load of pregnancy}

Pregnancy may substitute for the sensitising stimulus in rabbits ${ }^{9}$ and rats ${ }^{10}$ so that in these species only one stimulus is required to induce the generalised Shwartzman reaction (GSR) in the pregnant animal. This begs the question of what is the exact basis of the contribution of pregnancy to the endotoxic hypersensitivity. Some clues may be derived from the experiments of Stamler ${ }^{11}$ who found that, in rats, the characteristic lesions of GSR, particularly bilateral renal-cortical necrosis, could be brought about in pregnancy by a vitamin E-deficient diet but, remarkably, without the need for administered endotoxin. Vitamin $\mathrm{E}$ is an antioxidant vitamin functioning in lipid environments; the synergic pathogenic effect of vitamin-E deficiency and pregnancy implies that the metabolic effects of pregnancy are pro-oxidant.

\section{Increased pro-oxidant load-exogenous contribution of peroxidised oil}

Further experiments of MacKay ${ }^{12,13}$ and his colleagues showed that peroxidised oil given to pregnant animals may also induce GSR. The modified oil readily decomposes via free-radical 
reactions to produce lipid peroxidation in the host tissues, i.e., its derivatives set up the autocatalytic peroxidising chain reaction characteristic of lipid peroxidation. The results of the experiment suggest that the normal homeostatic control of peroxidation has been overwhelmed by the additional oxidising load-this time of external origin-superimposed on the pro-oxidant stress of pregnancy.

\section{Oxidative stress}

Therefore, oxidative stress would seem to qualify as an important contributor to the development of the endotoxic crisis. In the light of the now developed knowledge of phagocytic free-radical production, ${ }^{14}$ recent evidence is consistent with this view. ${ }^{15,16}$ In a model comparable to that of Suter and Kirsanow, Arthur et al. ${ }^{17}$ used killed Corynebacterium parvum to sensitise rats to the toxic effects of endotoxin on the liver. This pre-treatment increases (as does live BCG) the number of phagocytes, particularly in the liver and spleen. The authors believed that endotoxin enhanced the state of activation of hepatic macrophages, already partially activated by $C$. parvum and that reactive oxygen intermediates promoted liver injury. Their subsequent research ${ }^{18}$ supported this conclusion and showed that anti-oxidants, such as superoxide dismutase or allopurinol, reduced the toxicity of endotoxin.

Ethane, a by-product of lipid peroxidation, has been detected and measured in the air exhaled by mice poisoned by endotoxin. ${ }^{19}$ This is plain evidence of the peroxidation taking place in life and indicates that, in this experiment, the increased malonaldehyde (another by-product of lipid peroxidation) found in the tissues is not an artefact developing post mortem.

We have found that endotoxin administration led to increases in anti-oxidant production in the liver and spleen of BCG-infected mice. ${ }^{20,21}$ The macrophages from these animals were shown in vitro to produce free radicals after stimulation with endotoxin. ${ }^{22}$ Other workers ${ }^{23}$ have also confirmed that endotoxin induces anti-oxidants in lung and liver and that a consequence of exposure to endotoxin is lipid peroxidation, particularly in smooth muscle. ${ }^{24}$

\section{Altered phospholipid composition in sensitised animals}

We have found that BCG infection in mice affects the fatty-acid composition of phospholipids in peritoneal macrophages and liver cells. ${ }^{25}$ In particular, the ratio of polyunsaturated to saturated fatty acids was significantly increased, this being due mainly to increased incorporation of arachidonic acid into phospholipids.

Our results implied that BCG infection stimulated increased activity of acyl transferases. Factors influencing the control of membrane-phospholipid fatty-acid incorporation could have important regulatory functions for the response of phagocytes to stimuli such as endotoxin. Similar results have been obtained in lymphocytes and thymocytes from rabbits, and a correlation with increased membrane fluidity during lymphocyte stimulation has been suggested. ${ }^{26}$

Incorporation of unsaturated fatty acids, particularly arachidonic acid, into macrophage phospholipids may have effects on cellular phagocytic activity. It has been suggested that arachidonic acid released from membrane phospholipids in response to stimulation may have a role in the activation of the superoxide-generating system of these cells. ${ }^{27}$ Arachidonic acid may influence phagocyte function by directly stimulating the membrane-bound NADPH oxidase. ${ }^{28}$

\section{Eicosanoids and the fatty acids of membrane- phospholipid pools}

The complex inter-relationships of endotoxaemia and the production of arachidonic-acid derivatives have been reviewed by Flohé and Giertz. ${ }^{29}$ In shock, endotoxin brings about the release, either directly or through complement activities, of those pharmacologically active molecules; these may give rise to vasodilatation and altered permeability (prostacyclin), alterations to platelets (thromboxane) and possible hepatotoxicity (leukotrienes).

\section{Consequences of the altered membrane content of unsaturated fatty acids}

The increased polyunsaturated content of membranes makes them more vulnerable targets for free radicals and thus may contribute to oxidative stress due to lipid peroxidation. Free radicals produced by either the enzymatic (lipoxygenase, cycloxygenase) or non-enzymatic peroxidation of membrane lipids may initiate further breakdown of the unsaturated fatty acids to give autocatalytic lipid peroxidation. ${ }^{30}$ Moreover, products of the peroxidative process (oxygen and carbon-centred radicals, alkenals) are cytotoxic and may cause widespread tissue damage. ${ }^{31}$

The fatty-acid and phospholipid composition of biological membranes plays an important part in 
regulating intracellular activities, such as passage of solutes, receptor-ligand interactions, microviscosity, protein and enzyme reactions. Changes in phospholipid and fatty-acid composition will, therefore, have a profound effect on cellular and subcellular events. Changes in fatty-acyl moieties of phospholipids towards greater unsaturation may accompany stimulation of certain cells (lymphocytes, macrophages) to a state of hyper-reactivity. Enzymes taking part in this process, e.g., acyl transferases, may be important products of gene expression after stimulation of the cell by cytokines. ${ }^{32}$ Exchange of saturated fatty-acyl groups for unsaturated ones may lead to the increased

\section{REFERENCES}

1. Suter E, Kirsanow EM. Hyperreactivity to endotoxin in mice infected with mycobacteria. Induction and elicitation of the reactions. Immunology $1961 ; 4: 354-365$.

2. Sanarelli G. De la pathologénie du choléra. IX. Le choléra expérimental. Ann Inst Pasteur 1924; 38 : 11-72.

3. Shwartzman G. Studies in Bacillus typhosus toxic substances. I. Phenomenon of local skin reactivity to $B$. typhosus culture filtrate. $J$ Exp Med $1928 ; 48$ : 247-268.

4. Movat HZ, Burrowes CE, Cybulsky MI, Dinarello CA. Acute inflammation and a Shwartzman-like reaction induced by interleukin-I and tumour necrosis factor: synergistic action of the cytokines in the induction of inflammation on microvascular injury. Am J Pathol $1987 ; 129$ : 463-476.

5. Rothstein JL, Schreiber H. Synergy between tumour necrosis factor and bacterial products causes hemorrhagic necrosis and lethal shock in normal mice. Proc Natl Acad Sci USA 1988; 85: 607-611.

6. Billiau A, Heremans H, Vandekerckhove F, Dillen C. Antiinterferon-antibody protects mice against the generalized Shwartzman reaction. Eur J Immunol 1987; 17: 1851-1854.

7. Girardin E, Grau GE, Dayer J-M, Roux-Lombard P, Lambert P-H. Tumor necrosis factor and interleukin-I in the serum of children with severe infectious purpura. New Eng J Med 1988; 319: 397-400.

8. Valone SE, Rich EA, Wallis RS, Ellner JJ. Expression of tumour necrosis factor in vitro by human mononuclear phagocytes stimulated with whole Mycobacterium bovis BCG and mycobacterial antigens. Infect Immun 1988; 56: 3313-3315.

9. Apitz K. A study of the generalized Shwartzman phenomenon. J Immunol 1935; 29 : 255-266.

10. Wong T-C. A study on the generalized Shwartzman reaction in pregnant rats induced by bacterial endotoxin. $A m ~ J$ Obstet Gynecol 1962;84: 786-797.

11. Stamler FW. Fatal eclamptic disease of pregnant rats fed anti-vitamin E stress diet. Am J Pathol 1959; 35: $1207-$ 1231.

12. McKay DG, Wong T-C. Studies of the generalized Shwartzman reaction produced by diet. I. Pathology. $J$ Exp Med 1962; 115: 1117-1125.

13. Goldstein HB, McKay DG. Lipid peroxides and the dietinduced Shwartzman reaction. Am J Obstet Gynecol $1965 ; 91$ : 843-846. production of unsaturated fatty-acid products, particularly the eicosanoids such as prostaglandins and leukotrienes.

\section{Conclusion}

The background described above strongly suggests that modifications of the highly dynamic fatty-acid pools within the membrane phospholipids represent the nub of endotoxin susceptibility. The effect of the various cytokines on this aspect of the fate of fatty acids now warrants investigation in depth.

14. Babior BM, Kipnes RS, Curnutte JT. Biological defence mechanisms: the production of leukocytes of superoxide, a potential bactericidal agent. J Clin Invest 1973; 52: 741-744.

15. Jackson SK, Stark JM, Rowlands CC, Evans JC. Is gramnegative shock a free-radical-mediated condition? $J$ Chem Soc Faraday Trans 1. 1988; 84: 3243-3248.

16. Chaudhri G, Clark IA. Reactive oxygen species facilitate the in-vitro and in-vivo lipopolysaccharide-induced release of tumour necrosis factor. J Immunol 1989; 143 : 1290-1294.

17. Arthur MJP, Bentley IS, Tanner AR et al. Oxygen-derived free radicals promote hepatic injury in the rat. Gastroenterology 1985; 89: 1114-1122.

18. Arthur MJP, Kowalski-Saunders P, Wright R. Effect of endotoxin on release of reactive oxygen intermediates by rat hepatic macrophages. Gastroenterology 1988; 95 : 1588-1594.

19. Peavy DL, Fairchild EJ. Evidence for lipid peroxidation in endotoxin-poisoned mice. Infect Immun 1986; 52: 613616.

20. Stark JM, Jackson SK, Parton J. Increases in anti-oxidants after endotoxin in mice. In: Rice-Evans C, Dormandy $T$ (eds) Free radicals : chemistry, pathology and medicine. Richelieu Press. 1988: 187-210.

21. Stark JM, Jackson SK, Woodhead B, Ryley HC. Tissue oxidation after endotoxin. Bioelectrochem Bio-energ $1987 ; 18$ : 301-306.

22. Jackson SK, Stark JM, Rowlands CC, Evans JC. Electron spin resonance detection of oxygen-centred radicals in murine macrophages stimulated with bacterial endotoxin. Free Radic Biol Med 1989; 7: 165-170.

23. Brigham KL, Meyrick B, Berry LC, Repine JE. Antioxidants protect cultured bovine lung endothelial cells from injury by endotoxin. $J$ Appl Physiol 1987; 63: 840850 .

24. Yoshikawa T, Murakami M, Furukawa $Y$, Kato $H$, Takemura S, Kondo M. Lipid peroxidation and experimental disseminated intra-vascular coagulation in rats induced by endotoxin. Thromb Haemost 1983; 49: 214-216.

25. Jackson SK, Stark JM, Taylor S, Harwood JL. Changes in phospholipid fatty acid composition and triacyl-glycerol content in mouse tissues after infection with Bacille Calmette-Guérin. Br J Exp Pathol 1989; 70: 435-441.

26. Ferber E, De Pasquale GG, Resch K. Phospholipid metabolism of stimulated lymphocytes. Composition 
of phospholipid fatty acids. Biochim Biophys Acta 1975; 398: 364-376.

27. Phillips WA, Mossmann $H$, Ferber E. Changes in the incorporation of free fatty acids upon the stimulation of human polymorphonuclear leukocytes. $J$ Leuko Biol $1986 ; 39: 267-284$.

28. McPhail LC, Clayton CC, Snyderman R. A potential second messenger role for unsaturated fatty acids: activation of $\mathrm{Ca}^{2+}$-dependent protein kinase. Science $1984 ; 224$ : $622-625$.

29. Flohé L, Giertz H. Endotoxins, arachidonic acid and superoxide formation. Rev Infect Dis 1987; 9 Suppl 5: S553-S561.
30. Gardner HW. Oxygen radical chemistry of polyunsaturated fatty acids. Free Radic Biol Med 1989; 7: 65-86.

31. Benedetti A, Comporti M, Fulceri R, Esterbauer $H$. Cytotoxic aldehydes originating from the peroxidation of liver microsomal lipids. Identification of 4,5-dihydroxydecenal. Biochim Biophys Acta 1984; 792: 172181.

32. Bussolino F, Camussi G, Baglioni C. Synthesis and release of platelet-activating factor by human vascular endothelial cells treated with tumor necrosis factor or interleukin-I alpha. J Biol Chem 1988; 263: 1185611861 . 
